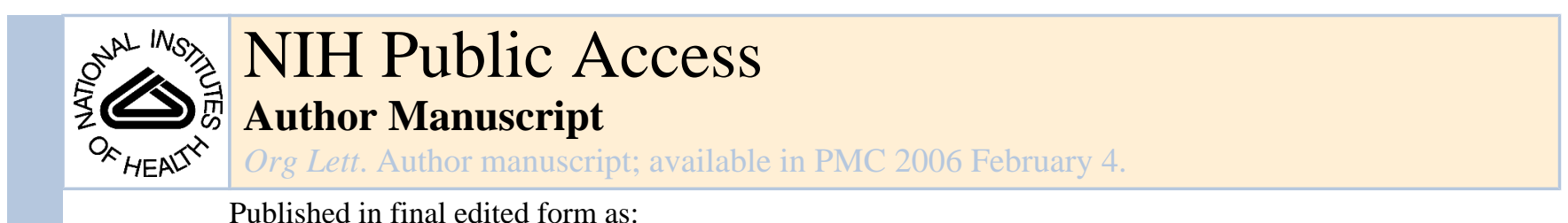

Published in final edited form as:

Org Lett. 2005 August 4; 7(16): 3573-3575.

\title{
Conjugated Polymer-Based Fluorescence Turn-On Sensor for Nitric Oxide
}

\author{
Rhett C. Smith, Andrew G. Tennyson, Mi Hee Lim, and Stephen J. Lippard* \\ Department of Chemistry, Massachusetts Institute of Technology, Cambridge, Massachusetts \\ 02139
}

\section{Abstract}
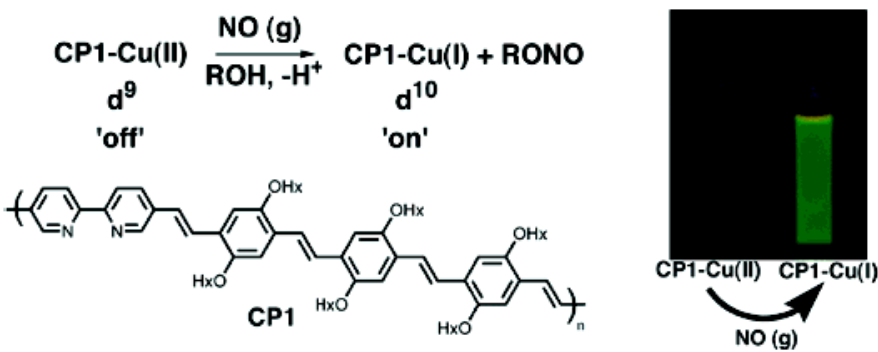

A turn-on fluorescent sensor for $\mathrm{NO}(\mathrm{g})$ in solution was synthesized using a bipyridyl-substituted poly ( $p$-phenylene vinylene) derivative (CP1) as the sensory scaffold. The action of $\mathrm{NO}(\mathrm{g})$ upon the $\mathrm{CP} 1-\mathrm{Cu}(\mathrm{II})$ complex reduces it to the $\mathrm{CP} 1-\mathrm{Cu}(\mathrm{I})$ complex with a concomitant 2.8 -fold increase in emission intensity. The reagent is selective for $\mathrm{NO}(\mathrm{g})$ versus other biological reactive nitrogen species, except for nitroxyl, and has a detection sensitivity limit of $6.3 \mathrm{nM}$.

The discovery that nitric oxide (NO) is the endothelium-derived relaxing factor astonished the scientific community. ${ }^{1}$ Since then, an even wider range of biological roles for NO have been elucidated. ${ }^{2} \mathrm{We}$ are interested in $\mathrm{NO}$ as a possible signaling agent in the central nervous system, 3 where it is proposed to mediate synaptic plasticity. ${ }^{4}$ The biological chemistry of NO has inspired researchers to devise techniques for its bioimaging, 5 of which turn-on fluorescence is especially attractive because of the demonstrated success of this strategy in real-time monitoring of other cellular signals. ${ }^{6}$ Neurological research in particular has benefited from the development of small-molecule fluorescent sensors specific for $\mathrm{Ca}^{2+6 \mathrm{~b} 7}$ or $\mathrm{Zn}^{2+}$. ${ }^{\text {Here }}$ we report a turn-on sensor for $\mathrm{NO}$ with $\mathrm{nM}$ sensitivity employing a $\pi$-conjugated polymer $(\mathrm{CP})$ as the fluorescent reporter.

The enhanced sensitivity of CPs vs small molecule-based sensors, together with their structural and optoelectronic tunability, renders them intriguing scaffolds for the design and construction of detection systems. ${ }^{9}$ We therefore investigated this class of materials for imaging NO by turn-on fluorescence, a resistivity-based CP sensor for NO having been previously described. 10 The successful realization of CPs for fluorescence-based detection of NO, in the form of a $\mathrm{CP}$-copper complex that exhibits a turn-on response to $\mathrm{NO}$ in solution, represents an advantageous new strategy with many possible applications.

lippard@mit.edu.

Supporting Information Available: Experimental details, absorption and emission spectra, EPR spectra, and details of sensitivity and selectivity measurements. This material is available free of charge via the Internet at http://pubs.acs.org. 
Previously, we reported transition metal-based NO sensors that involved displacement of a fluorescent ligand from a mono- or dimetallic center with attendant turn-on of fluorescence, one of which is reversible (Scheme $1 \mathrm{a}, \mathrm{L}=$ fluorescent ligand). ${ }^{11}$ More recent work unveiled a related approach, ${ }^{12}$ involving NO-induced copper redox chemistry, ${ }^{13}$ with net conversion of fluorophore-labeled, paramagnetic (quenched) $\mathrm{Cu}$ (II) complexes to a diamagnetic (fluorescent) $\mathrm{Cu}(\mathrm{I})$ state (Scheme $1 \mathrm{~b}$ ). This mechanism has been considered as a possibility for colorimetric NO sensing. 14

In further pursuit of the latter strategy, we prepared a series of CPs integrating copper-binding units at defined intervals and screened their relative fluorescence intensities in both $\mathrm{CP}-\mathrm{Cu}(\mathrm{I})$ and $\mathrm{CP}-\mathrm{Cu}(\mathrm{II})$ forms, anticipating turn-on NO detection by the process depicted in Scheme 1b. ${ }^{15}$ A poly( $p$-phenylene vinylene) (PPV) derivative incorporating periodic bipyridyl units along the main chain displayed the most suitable properties for further investigation (CP1, Figure $1, \mathrm{Hx}=n$-hexyl). A structurally related $\mathrm{CP}$ is reportedly quenched in the presence of $\mathrm{Cu}(\mathrm{II})$, whereas only moderate quenching occurs with added $\mathrm{Cu}(\mathrm{I}) .{ }^{16} \mathrm{~A}$ careful study of the structural and photophysical characteristics of poly( $p$-phenylene ethynylene)/bipyridyl- $\mathrm{Cu}(\mathrm{I})$ complexes has recently been undertaken. ${ }^{17}$ This work indicates that stable complexes exist with two bipyridyl units per $\mathrm{Cu}(\mathrm{I})$, indicating that only 0.5 equiv of $\mathrm{Cu}(\mathrm{I})$ are necessary to attain maximum quenching of polymer luminescence, as independently observed in the present study (Supporting Information).

CP1 is a bright red-orange solid $\left(\lambda_{\max }=462 \mathrm{~nm}\right)$ with strong fluorescence emission centered at $542 \mathrm{~nm}(\Phi=0.30)$. Upon addition of 1 equiv of $\mathrm{Cu}(\mathrm{OTf})_{2}$ to a solution of $\mathbf{C P 1}$, the integrated fluorescence intensity was quenched 4-fold, whereas addition of 1 equiv of $\left[\mathrm{Cu}(\mathrm{NCMe})_{4}\right]$ $\left[\mathrm{BF}_{4}\right]$ decreased the fluorescence by $\sim 30 \%$ (Figure 2). ${ }^{15}$ Adding $>0.5$ equiv of $\mathrm{Cu}(\mathrm{II}$ ) afforded little additional emission quenching.

Introduction of 300 equiv of $\mathrm{NO}$ (g) to the $\mathbf{C P 1}-\mathrm{Cu}$ (II) complex rapidly ( $<1 \mathrm{~min}$ ) increased the integrated emission by 2.8 -fold, producing a fluorescence spectrum similar to that of the CP1-Cu(I) complex (Figure 2). NO (g) did not alter the fluorescence of CP1 in the absence of $\mathrm{Cu}(\mathrm{II})$.

In the proposed mechanism, Scheme $1 b$, protons are formed that could affect the fluorescence of CP1. Protons alone, however, decrease the emission from bipyridyl-PPVs. ${ }^{18}$ Using a handheld UV lamp, a decrease in emission was qualitatively confirmed in the current case following addition of $3 \mu \mathrm{L}$ of glacial acetic acid to $5 \mathrm{~mL}$ of a $2 \mu \mathrm{M}$ solution of $\mathbf{C P 1}$ in $4: 1$ $\mathrm{CH}_{2} \mathrm{Cl}_{2} / \mathrm{EtOH}$.

Following initial trials with NO (g), we examined the selectivity of the sensor for nitric oxide vs other biologically relevant reactive nitrogen species (RNS). In parallel with ongoing work in our laboratory, ${ }^{19}$ we evaluated a nitrosothiol (SNAP, $S$-nitroso- $N$-acetylpenicillamine), a nitroxyl (HNO) donor (Angeli's salt, $\left.\mathrm{Na}_{2} \mathrm{~N}_{2} \mathrm{O}_{3}\right),{ }^{20}$ and a nitrosonium $\left(\mathrm{NO}^{+}\right.$) source $\left(\mathrm{NOBF}_{4}\right)$ for their ability to alter the emission spectra of CP1, CP1-Cu(I), or CP1-Cu(II). These donors were selected on the basis of their commercial availability in high purity and well-studied kinetics of RNS formation. ${ }^{22}$ None of the donors (50 equiv of SNAP, 50 equiv of $\mathrm{NOBF}_{4}$, or 16 equiv of Angeli's salt, $\mathrm{Na}_{2} \mathrm{~N}_{2} \mathrm{O}_{3}$ ) induced a change in the emission spectra of CP1 or CP1-Cu(I). When 50 equiv of SNAP was added to CP1-Cu(II), a 1.5-fold turn-on of fluorescence occurred slowly over $2 \mathrm{~h}$, in accord with the known ability of cupric ion to catalyze the release of NO from nitrosothiols. ${ }^{22 \mathrm{e}}$ The same effect was observed upon reversing the order of $\mathrm{Cu}$ (II) and SNAP addition, in which case the expected 4-fold quenching occurred immediately upon $\mathrm{Cu}$ (II) addition, followed by a slow turn-on. This control indicates that the presence of excess SNAP does not interfere with $\mathrm{Cu}$ (II) binding by CP1. A full $24 \mathrm{~h}$ was required following addition of SNAP before a turn-on response (2.1-fold) similar to that evoked 
by NO (g) was attained. Because of the significantly longer time for SNAP $(24 \mathrm{~h})$ vs NO ( $<1$ $\mathrm{min}$ ) to elicit a fluorescence response, nitrosothiols should not be considered as seriously interfering analytes.

The addition of 50 equiv of $\mathrm{NOBF}_{4}$ did not affect the fluorescence of solutions of $\mathbf{C P 1}$ or of preformed $\mathbf{C P 1}-\mathrm{Cu}(\mathrm{I})$ or $\mathbf{C P 1}-\mathrm{Cu}(\mathrm{II})$. When $\mathrm{Cu}$ (II) was added to a solution of $\mathbf{C P 1}$ containing 50 equiv of $\mathrm{NOBF}_{4}$, the emission spectrum was the same as that of $\mathbf{C P 1}-\mathrm{Cu}(\mathrm{II})$. In the presence of $\mathrm{EtOH}, \mathrm{NOBF}_{4}$ will form EtONO. The solution resulting from addition of $\mathrm{NOBF}_{4}$ to $\mathbf{C P 1}$ $\mathrm{Cu}(\mathrm{I})$ was therefore expected to contain the same species present in the reaction of $\mathbf{C P 1}-\mathrm{Cu}$ (II) with NO. These two solutions exhibited identical emission spectra.

Although no response was elicited by nitroxyl with $\mathbf{C P 1}-\mathrm{Cu}(\mathrm{I})$, it is noteworthy that an immediate 2.8-fold increase occurred upon reaction of $\mathbf{C P 1}-\mathrm{Cu}$ (II) with 50 equiv of nitroxyl, formed from decomposition of Angeli's salt. The spectrum produced was nearly identical to

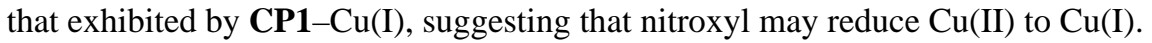

The effect of $\mathrm{O}_{2}$ was also investigated as another possible interfering biological species. Aeration of a cuvette containing a nitrogen-purged $\mathbf{C P 1}-\mathrm{Cu}$ (II) solution slightly decreased the integrated fluorescence $(\sim 6 \%)$. This response is presumably due the ability of $\mathrm{O}_{2}$ to serve as a collisional quencher and is within the error of detection.

The sensitivity of the $\mathbf{C P 1}-\mathrm{Cu}$ (II) complex to NO was evaluated by addition of progressively lower concentrations of SNAP to a $630 \mathrm{nM}$ solution of the sensor. On the basis of multiple measurements versus an emission standard, NIST-issued quinine sulfate dihydrate, we determined a $10 \%$ increase in integrated emission to be the lowest quantifiable change discernible at our instrumental detection limit. By using this method, we computed a sensitivity of about $6.3 \mathrm{nM}$ for the $\mathbf{C P 1}-\mathrm{Cu}(\mathrm{II})$ system.

Although previous work has provided strong evidence for the mechanism presented in Scheme $1 b,{ }^{13}$ we carried out a number of additional checks to confirm its validity in the present context. The strongest supporting evidence is the near perfect match of emission spectra derived from CP1-Cu(I), CP1-Cu(I)/NO ${ }^{+}$, and CP1-Cu(II)/NO. Exposure of CP1-Cu(II) to NO (g) in the absence of EtOH, which is required to form RONO in the proposed mechanism, did not produce an increase in fluorescence. Finally, the expected diminution of the EPR signal of CP1-Cu(II) occurred upon addition of 1 equiv of $\mathrm{NO}$, confirming reduction to $\mathrm{Cu}(\mathrm{I})$. When 1 equiv of $\mathrm{Cu}$ $(\mathrm{OTf})_{2}$ was added to a solution of $\mathbf{C P 1}$ ( 0.5 equiv bind) followed by 1 equiv of $\mathrm{NO}(\mathrm{g})$, the integrated signal decreased by $45 \%$, indicating that only $\mathbf{C P 1}$-coordinated $\mathrm{Cu}$ (II) is reduced to $\mathrm{Cu}(\mathrm{I})$. No bands attributable to stable copper nitrosyls were observed by IR spectroscopy.

Despite the strong evidence and precedence for the proposed mechanism, we note that, in addition to the $\mathrm{d}^{9} \rightarrow \mathrm{d}^{10}$ transformation that occurs upon reduction, some degree of ligand rearrangement or other structural alteration, to which CP emission is very sensitive, ${ }^{17,21}$ could play a role in the observed sensory response. Work in progress with small-molecule model compounds will elucidate such possibilities.

The system reported here represents an early manifestation of a new strategy for the fluorescent detection of NO. To the best of our knowledge, it also signifies the first fluorescence-based sensor for NO employing a conjugated polymer scaffold. ${ }^{10}$ Studies have commenced to identify additional transition metal-conjugated polymer complexes for improved sensory response, devise specificity for $\mathrm{NO}$ over nitroxyl, and prepare highly fluorescent water-soluble derivatives for biological imaging of nitric oxide. ${ }^{21}$ 


\section{Supplementary Material}

Refer to Web version on PubMed Central for supplementary material.

\section{Acknowledgements}

This work was supported by NSF Grant CHE-0234951. R.C.S. and A.G.T. thank the NIH and NSF for Fellowships. The MIT DCIF NMR spectrometer was funded through NSF Grants CHE-9808061 and DBI-9729592.

\section{References}

1. a Ignarro LJ. Angew Chem, Int Ed 1999;38:1882-1892. b Furchgott RF. Angew Chem, Int Ed 1999;38:1870-1880. c Murad F. Angew Chem, Int Ed 1999;38:1856-1868.

2. (a) Richter-Addo, G. B.; Legzdins, P. Metal Nitrosyls; Oxford University Press: New York, 1992.(b) Butler, A.; Nicholson, R. Life, Death and Nitric Oxide; Royal Society of Chemistry: Cambridge, UK, 2003. c Ricciardolo FLM, Sterk PJ, Gaston B, Folkerts G. Phys Rev 2004;84:731-765. d Cals-Grierson MM, Ormerod AD. Nitric Oxide 2004;10:179-193. [PubMed: 15275864] e Toda N, Okamura T. Pharm Rev 2003;55:271-324. [PubMed: 12773630] f Wei CC, Crane BR, Stuehr DJ. Chem Rev 2003;103:2365-2383. [PubMed: 12797834]

3. a Bon CLM, Garthwaite J. J Neurosci 2003;23:1941-1948. [PubMed: 12629199] b Pepicelli O, Raiteri M, Fedele E. Neurochem Int 2004;45:787-797. [PubMed: 15312973]

4. Huang EP. Curr Biol 1997;7:R141-R143. [PubMed: 9162474]

5. Nagano T, Yoshimura T. Chem Rev 2002;102:1235-1269. [PubMed: 11942795]

6. a Zhang J, Campbell RE, Ting AY, Tsien RY. Nat Rev Mol Cell Biol 2002;3:906-918. [PubMed: 12461557] b Zacharias DA, Baird GS, Tsien RY. Curr Opin Neurobiol 2000;10:416-421. [PubMed: 10851181]

7. Miyawaki A. Curr Opin Neurobiol 2003;13:591-596. [PubMed: 14630223]

8. a Burdette SC, Lippard SJ. Proc Nat Acad Sci 2003;100:3605-3610. [PubMed: 12655069] b Jiang P, Guo Z. Coord Chem Rev 2004;248:205-229. c Chang CJ, Lippard SJ. Metal Ions Biol Syst 2005;45in press.

9. a McQuade DT, Pullen AE, Swager TM. Chem Rev 2000;100:2537-2574. [PubMed: 11749295] b Swager TM. Acc Chem Res 1998;31:201-207.

10. Shioya T, Swager TM. Chem Commun 2002:1364-1365.

11. a Franz KJ, Singh N, Lippard SJ. Angew Chem, Int Ed 2000;39:2120-2122. b Franz KJ, Singh N, Spingler B, Lippard SJ. Inorg Chem 2000;39:4081-4092. [PubMed: 11198863] c Hilderbrand SA, Lim MH, Lippard SJ. J Am Chem Soc 2004;126:4872-4878. d Lim MH, Lippard SJ. Inorg Chem 2004;43:6366-6370. [PubMed: 15446885]

12. Lim, M. H.; Lippard, S. J. 2005, submitted for publication.

13. Tran D, Skelton BW, White AH, Laverman LE, Ford PC. Inorg Chem 1998;37:2505-2511.

14. Dacres H, Narayanaswamy R. Sens Act B 2003;90:222-229.

15. Details of the full set of polymers examined will be reported elsewhere.

16. Wang B, Wasielewski MR. J Am Chem Soc 1997;119:12-21.

17. Kokil A, Yao P, Weder C. Macromolecules 2005;38:3800-3807.

18. Eichen Y, Nakhmanovich G, Gorelik V, Epshtein O, Poplawski JM, Ehrenfreund E. J Am Chem Soc 1998;120:10463-10470.

19. Tennyson, A. G.; Lippard, S. J. Manuscript in preparation.

20. Bartberger MD, Lin W, Ford E, Miranda KM, Switzer C, Fukuto JM, Farmer PJ, Wink PA, Houk KN. Proc Natl Acad Sci USA 2002;99:10958-10963. [PubMed: 12177417]

21. a Wang D, Gong X, Heeger PS, Rininsland F, Bazan GC, Heeger AJ. Adv Funct Mater 2003;13:463467. b Kuroda K, Swager TM. Chem Commun 2003:26-27. c Xu QH, Gaylord BS, Wang S, Bazan GC, Moses D, Heeger AJ. Proc Natl Acad Sci USA 2004;101:11634-11639. [PubMed: 15282375]

22. a Bonner FT, Ravid B. Inorg Chem 1975;14:558-563. b Bazylinski DA, Hollocher TC. Inorg Chem 1985;24:4285-4288. c Singh RJ, Hogg N, Joseph J, Kalyanaraman B. J Biol Chem 1996;271:1859618603. [PubMed: 8702510] d Williams DLH. Met Enzymol 1996;268:299-308. e Smith JN, 
Dasgupta TP. Nitric Oxide 2000;4:57-66. [PubMed: 10733873] f Chen Y, Irie Y, Keung WM, Maret W. Biochem 2002;41:8360-8367. [PubMed: 12081484] 


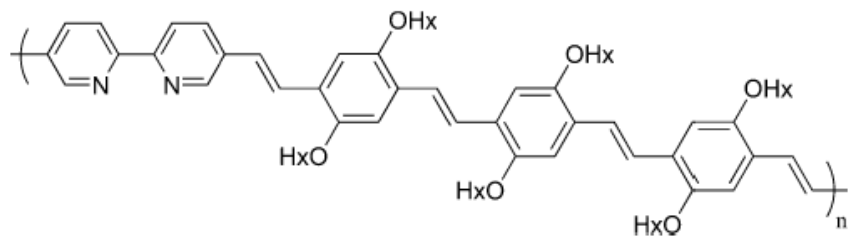

Figure 1.

Structure of CP1. 


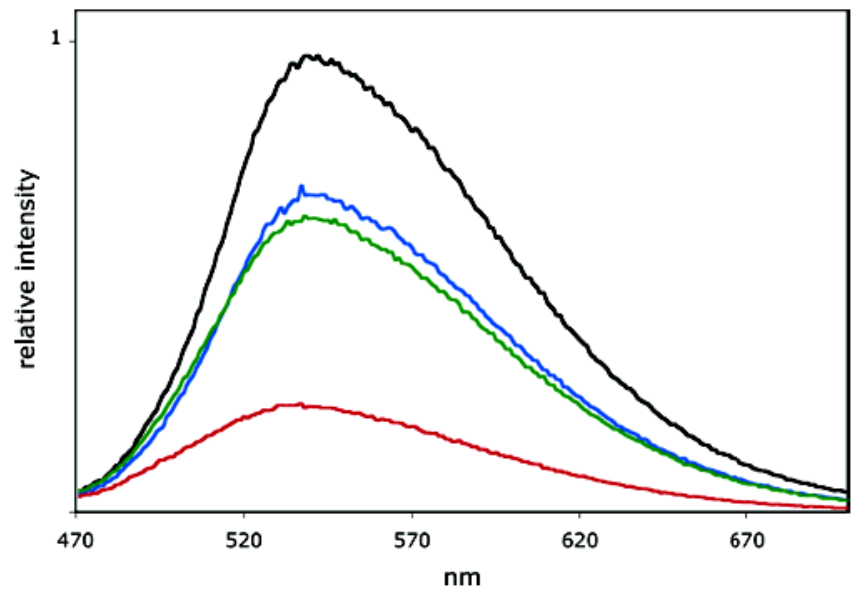

Figure 2.

Emission spectra of CP1 (black), CP1-Cu(I) (green), CP1-Cu(II) (red), and CP1-Cu(II) immediately following addition of 300 equiv of NO $(\mathrm{g})$. All measurements were made in 4:1 $\mathrm{CH}_{2} \mathrm{Cl}_{2} / \mathrm{EtOH}$. 
(a) Fluorophore displacement

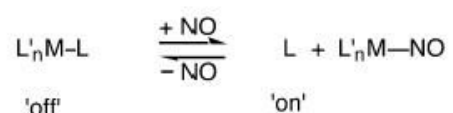

(b) Conversion to a diamagnetic complex

$$
\mathrm{LCu}^{2+}+\mathrm{NO} \stackrel{\mathrm{ROH}}{\longrightarrow} \mathrm{LCu}^{1+}+\mathrm{RONO}+\mathrm{H}^{+}
$$

Scheme 1.

Strategies for Fluorescent Detection of Nitric Oxide 